\title{
Non-Isothermal Crystallization Kinetics of a Rapidly Solidified as-Cast TiZrHfNiCu High Entropy Bulk Metallic Glass
}

\author{
Norhuda Hidayah Nordin, Faiz Syazwan Mohamad, Nur Ayuni Jamal \\ International Islamic University Malaysia, Selangor, Malaysia \\ Email: norhudahidayah@iium.edu.my
}

How to cite this paper: Nordin, N.H., Mohamad, F.S. and Jamal, N.A. (2020) Non-Isothermal Crystallization Kinetics of a Rapidly Solidified as-Cast TiZrHfNiCu High Entropy Bulk Metallic Glass. World Journal of Engineering and Technology, 8, 280-295.

https://doi.org/10.4236/wjet.2020.83023

Received: April 13, 2020

Accepted: July 18, 2020

Published: July 21, 2020

Copyright $\odot 2020$ by author(s) and Scientific Research Publishing Inc. This work is licensed under the Creative Commons Attribution International License (CC BY 4.0).

http://creativecommons.org/licenses/by/4.0/

(c) (i) Open Access

\begin{abstract}
This paper aims to investigate the thermal behavior and crystallization kinetics of TiZrHfNiCu high entropy bulk metallic glass (HE-BMG) alloy using the standard procedure of Differential Scanning Calorimetric (DSC) annealing technique. The alloy was produced using an arc melting machine with a critical diameter of $1.5 \mathrm{~mm}$. The crystallization kinetics and phase transformation mechanism of TiZrHfNiCu HE-BMG was investigated under the isochronal condition at a single heating run based on the Johnson-MehlAvrami (JMA) theory. In isochronal heating, the apparent activation energy for glass transition and crystallization events was analyzed by Kissinger and Ozawa methods. The average activation energy value for crystallization of TiZrHfNiCu amorphous alloys in isochronal modes was $226.41 \mathrm{~kJ} / \mathrm{mol}$ for the first crystallization and $297.72 \mathrm{~kJ} / \mathrm{mol}$ for second crystallization stages. The crystallization mechanism of the first step was dominated by two- and three-dimensional growth with increasing nucleation rate, while the crystallization mechanism in the second stage was dominated by two-dimensional crystallization growth with a constant nucleation rate. The diffusion mechanism result proved the theory of sluggish atomic diffusion of HEA at elevated temperature.
\end{abstract}

\section{Keywords}

Crystallization Kinetics, High Entropy Bulk Metallic Glass, Phase Transformation, Sluggish Diffusion

\section{Introduction}

High Entropy Alloys (HEAs) and Bulk Metallic Glasses (BMGs) are two types of novel materials that exhibit unique physical and mechanical properties [1] [2]. 
HEAs have been defined as a near equiatomic ratio of multi-component alloys that form simple phases of body-centered cubic (BCC), face-centered cubic (FCC) or hexagonal closed packed (HCP) that resulted from high entropy effect [1] while BMGs is a non-crystalline metallic alloy with a disordered atomic-scale structure that produced by rapid cooling method [3].

Amorphous HEAs or high entropy bulk metallic glasses (HE-BMGs) appear to have a random distribution of atomic arrangement compared to regular HEAs. Moreover, HE-BMGs have shown promising potential to express the advantages of HEAs and BMGs in tandem. High entropy effect in HE-BMGs results in low viscosity of the alloy melt thus it is expected to produce low glass-forming ability (GFA) alloy. In contrast, it has been suggested that the HE-BMGs may have a higher thermal stability and deliberate crystallization process due to its sluggish atomic diffusion [1] [4]. The theory of crystallization in glassy alloys can be explained by considering the structure and the kinetics of crystallization. Numerous researches on the investigation of kinetics have been presented with different approaches in clarifying the crystallization process, including mechanism, activation energy and correlation between kinetics and structural in amorphous alloys. The first report on crystallization kinetics of HE-BMG was published by Gong, Yao, and Ding in 2015 by choosing $\mathrm{Ti}_{16.7} \mathrm{Zr}_{16.7} \mathrm{Hf}_{16.7} \mathrm{Cu}_{16.7} \mathrm{Ni}_{16.7} \mathrm{Be}_{16.7}$ as composition using both non-isothermal and isothermal modes [5].

Some alloys undergo structural transformation upon a change in thermal conditions, which then affect its properties in applications [6]. Therefore, studies of the kinetics of phase transformation in the metastable nature of amorphous structure are crucial in determining the thermal stability of these alloys since it tends to evolve towards a more stable state when it is heated to a temperature higher than their glass transition temperature $\left(T_{g}\right)$. Hence, the study of crystallization kinetics and mechanism of each phase is crucial in understanding the crystallization transformation kinetics and thermal stability of HE-BMGs. Besides, studies of crystallization kinetics may provide routes of the transformation of the alloys from the randomly arranged structure into an ordered structure when the alloy is approaching equilibrium. The crystallization of amorphous alloys upon heating can be performed in several ways. Generally, two basic methods are considered for crystallization kinetics studies for amorphous alloys, include isothermal and non-isothermal (isochronal).

Previous works have highlighted few methods for crystallization kinetics studies for amorphous alloys. It can be measured theoretically using JohnsonMel-Avrami-Kolmogorov (JMAK) equation by considering four assumptions: 1) isothermal crystallization state, 2) growth rate of new phases is controlled only by temperature 3) random and homogeneous nucleation of the second phase and 4) low anisotropy of the growing phase. Therefore, the JMAK equation has been utilized in most research works for analyzing crystallization kinetics in isothermal conditions [7] [8] [9] [10] [11]. Moreover, the JMAK equation can also be extended to be employed in non-isothermal conditions with the assumption 
that the overall nucleation process occurs during the initial crystallization process and becomes neglected afterward [12]. This method is also widely used for non-isothermal crystallization kinetics studies in various amorphous alloys [13] [14] [15] [16] [17]. Different models have been proposed to measure the $E_{a}$ for non-isothermal conditions includes the Ozawa-Flynn-Wall method [18], Kissinger method [19], and Augis-Bennett method [20]. All of them are derived from Johnson Mehl Avrami (JMA) method having an Arrhenian temperature dependence.

However, there are issues reported which discussed regarding the applicability of the Kissinger model [21], particularly to determine the glass transition activation energy. It was found that the Kissinger method was influenced by the thermal history of the sample that differed from the value obtained from the simulations [22]. It was suggested that the Moynihan model utilized the concept of "fictive temperature" [23], which can be used to represent relevant cases of structural relaxation behavior. In contrast, the Kissinger model is not capable of determining the activation energy for glass transition correctly since it only considers the simple thermal activated process. Therefore, the Moynihan model was claimed to be more accurate than the Kissinger model since it considers the main features of structural relaxation behavior [24]. However, [25] was compared the apparent activation energies of some novel near-equiatomic high-entropy bulk metallic glasses samples using Kissinger, Moynihan, Ozawa, and Boswell methods and found that the calculated value of apparent activation energy, $E_{g}$ and $E_{x}$ for Kissinger and Moynihan are almost the same.

In this work, the crystallization kinetics of TiZrHfNiCu HE-BMG was investigated by isochronal condition using the standard procedure of Differential Scanning Calorimetric (DSC) annealing technique. The mechanism of nucleation and growth of this alloy obtained from the calculated kinetics parameters can be used to determine the thermal behavior of this alloy at elevated temperature. This will also prove the sluggish diffusion behavior of HE-BMGs at elevated temperatures.

\section{Experimental}

TiZrHfNiCu HE-BMG in equal atomic proportion (at.\%) was prepared by arc melting under Ti-gettered argon atmosphere using highly pure elements, which were above $99.5 \mathrm{wt} \%$. The alloys were melted for at least five times to ensure homogeneity. The alloy ingots were suction cast into a water-cooled copper mold with dimensions of $1.5 \mathrm{~mm}, 2 \mathrm{~mm}$, and $3 \mathrm{~mm}$ diameters and $30 \mathrm{~mm}$ length. Meanwhile, rapidly quenched ribbons form was prepared by re-melting the alloy ingots in quartz crucible by induction melting while ejecting with a pressure of $40 \mathrm{kPa}$ through a nozzle onto a $\mathrm{Cu}$ wheel rotating with a surface velocity at $40 \mathrm{~m} / \mathrm{s}$.

\subsection{Crystallization Kinetics Experiments}

The experiments were conducted using a Perkin Elmer DSC-diamond, with a 
computerized data acquisition system. The sample with $10-20 \mathrm{mg}$ in weight was put in the aluminum pan and heated from $200^{\circ} \mathrm{C}-500^{\circ} \mathrm{C}$ with a different heating rate at $20 \mathrm{~K} / \mathrm{min}$ to $80 \mathrm{~K} / \mathrm{min}$. Purified argon gas was used throughout the experiment. The onset crystallization temperature was defined as the slope of the tangent intersection in the DSC curve.

\subsection{Characterizations}

Structures of the as-cast and melt-spun ribbons were examined by X-ray diffraction (XRD) using (Phillips D5000) $\mathrm{Cu}-\mathrm{K} \alpha$ radiation. It was then marked as $\mathrm{S} 1$, $\mathrm{S} 2$, S3, and S4 for ribbon, $1.5 \mathrm{~mm}, 2 \mathrm{~mm}$, and $3 \mathrm{~mm}$, respectively. Thermal analysis of the samples was carried out using (DSC, Perkin-Elmer Instruments, diamond) from $200^{\circ} \mathrm{C}-500^{\circ} \mathrm{C}$ at $20 \mathrm{~K} / \mathrm{min}$ to determine glass transition temperature $\left(T_{g}\right)$ and crystallization temperature $\left(T_{x}\right)$.

\section{Result and Discussion}

\subsection{Alloys Design}

The multicomponent high entropy alloys, TiZrHfNiCu HE-BMG alloys was reproduced from [26] based on the idea of forming glassy high entropy alloys from the equal concentration of constituent elements which did not contain any host element. The selection of the elements well in accordance with the three empirical rules is described by Inoue [27]. In order to determine the formability of solid solution in this alloy, thermodynamic and electronic parameters of the alloys include the enthalpy of mixing $\left(\Delta H_{\text {mix }}\right)$, the entropy of mixing $\left(\Delta S_{\text {mix }}\right)$, atomic size difference $(\delta)$, electronegativity difference $\left(\Delta_{\chi}\right)$, and valence electron concentration (VEC) were calculated as shown in Table 1, where the relationship of enthalpy of mixing in each element pair is shown in Figure 1. This calculation has been used extensively for phase formation in predicting HEAs and BMGs [28] [29].

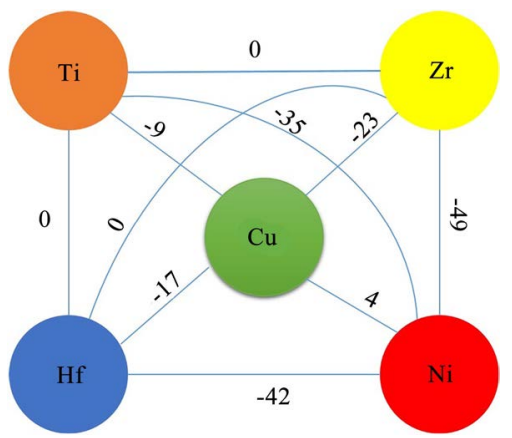

Figure 1. Relationship of heat of mixing among constituent elements in the TiZrHfNiCu HE-BMG alloy [26].

Table 1. Parameters of $\Delta H_{\text {mix }}, \Delta S_{\text {mix }}, \delta$ and $\Delta \chi$ for TiZrHfNiCu HE-BMG [26].

\begin{tabular}{ccccc}
\hline VEC & $\Delta \chi$ & $\delta$ & $\Delta H_{\text {mix }}$ & $\Delta S_{\text {mix }}$ \\
\hline 6.6 & 0.27 & 10.32 & -27.36 & 13.38
\end{tabular}


The relationship of the heat of mixing among the constituent elements in Figure 1 shows that $\mathrm{Ni}$ and $\mathrm{Cu}$ possessed negative heats of mixing against $\mathrm{Ti}, \mathrm{Zr}$ and $\mathrm{Hf}$. Ni provided larger absolute values compared to $\mathrm{Cu}$ with $\mathrm{Ti}, \mathrm{Zr}$, and $\mathrm{Hf}$, which resulted in the strong attraction of interatomic forces between those elements that contributed to the formation of the glassy phase in the alloys as calculated according to Miedema's model [30]. On the other hand, $\mathrm{Ni}$ and $\mathrm{Cu}$ were located next to each other in the periodic table which results in positive enthalpy of mixing. The thermodynamic analysis revealed that the glass-forming behaviour of $\mathrm{Zr}$ and $\mathrm{Hf}$ was similar, whereas it was different from that of $\mathrm{Ti}$. The preferred formation of amorphous phases in the system was attributed to high negative mixing enthalpy between the constituent elements.

The atomic size ratios in the present system were the second factor for the formation of the bulk glassy alloy. Table 2 has summarized the atomic size ratios among the elements in the present system. The atomic size ratios among $\mathrm{Ti}, \mathrm{Zr}$ and $\mathrm{Hf}$ were less than $10 \%$. While, the atomic size ratios for $\mathrm{Ni}$ and $\mathrm{Cu}$ with $\mathrm{Ti}$, $\mathrm{Zr}$ or Hf were more significant than $12 \%$. Therefore, the more massive negative heats of mixing for $\mathrm{Ni}$ with $\mathrm{Ti}, \mathrm{Zr}$ and $\mathrm{Hf}$ might be suggested as the main reason for the formation of the bulk glassy while the atomic size ratio of $\mathrm{Ni}$ and $\mathrm{Cu}$ with $\mathrm{Ti}, \mathrm{Zr}$ and $\mathrm{Hf}$ could be considered as an additional factor that contributed to the glass formation in $\mathrm{Ti}_{20} \mathrm{Zr}_{20} \mathrm{Hf}_{20} \mathrm{Cu}_{20} \mathrm{Ni}_{20}$ alloy.

\subsection{XRD Analysis}

Figure 2 shows the XRD patterns of the equiatomic TiZrHfNiCu samples with cooling rate variations while Table 3 summarised the findings from the patterns. According to the diffractogram, it was clearly shown a broadened peak of 1.5 $\mathrm{mm}$ as-cast rod and $40 \mathrm{~m} / \mathrm{s}$ melt-spun ribbon at $2 \theta=30^{\circ}-45^{\circ}$, indicating that the alloy possessed fully amorphous structure. The partially amorphous structure could be observed in a $2 \mathrm{~mm}$ rod due to the existence of halo humps with some crystalline peaks at a lower angle $\left(2 \theta=30^{\circ}-45^{\circ}\right)$. Since the sample composes of a mixture of amorphous and crystalline structures, the peaks are less intense and not clear at a lower angle $\left(20^{\circ}\right.$ to $\left.30^{\circ}\right)$. It may because of the small sample size, which needs a smaller step size and slower scan rate to get ideally sharp profile data, particularly at a lower angle.

\subsection{DSC Analysis}

\section{Non-Isothermal Annealing}

Figure 3 shows typical DSC curves for the amorphous TiZrHfNiCu HE-BMG alloy at five different heating rates $\left(10,20,40,60\right.$, and $\left.80 \mathrm{~K} \cdot \mathrm{min}^{-1}\right)$. All DSC curves in the temperature range of $650-850 \mathrm{~K}$ showed an endothermic event corresponding to the glass transition followed by two exothermic crystallization peaks, which indicated the multi-stage crystallization process of the alloy. Therefore, the crystallization process of this alloy was somewhat complicated, in contrast to most of the conventional metallic glasses. It was suggested that the multiple exothermic peaks were attributed to the decomposition of the metallic bonding 
that leads to the crystallization process [31]. The onset of the glass transition temperature, $T_{g}$ and crystallization temperature, $T_{x}$ along with peak temperature for each crystallization events, and supercooled liquid region $\left(\Delta T_{x}\right)$ were listed in Table 4. Apparently, the temperatures of all peaks shifted to a higher temperature, and the heat flow became more significant with the increasing heating rate, which showed that the alloy possessed an apparent thermodynamic effect. This scenario also represented different thermal activation of each step in the crystallization process. Interestingly, it was found that the second crystallization peak at $40 \mathrm{~K} / \mathrm{min}$ is slightly intense than at $60 \mathrm{~K} / \mathrm{min}$. Theoretically, a sharp peak represents a faster rate of transformation with more considerable enthalpy change that usually occurs at a higher heating rate [32]. Nevertheless, a slightly intense peak does not necessarily mean a higher rate of transformation since it probably happens due to a higher volume of materials tested or element additions in the chemical composition of the sample during the testing.

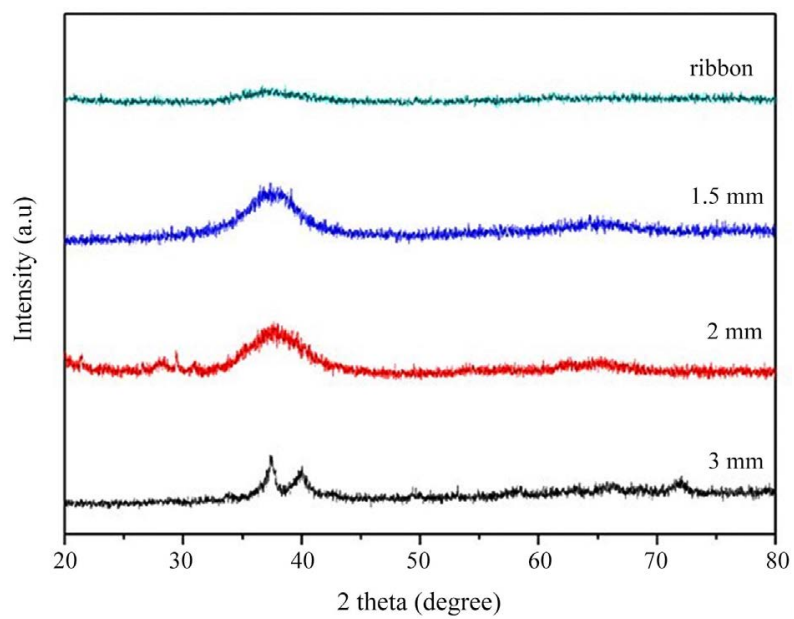

Figure 2. XRD patterns of the as prepared TiZrHfNiCu alloy at different casting diameter.

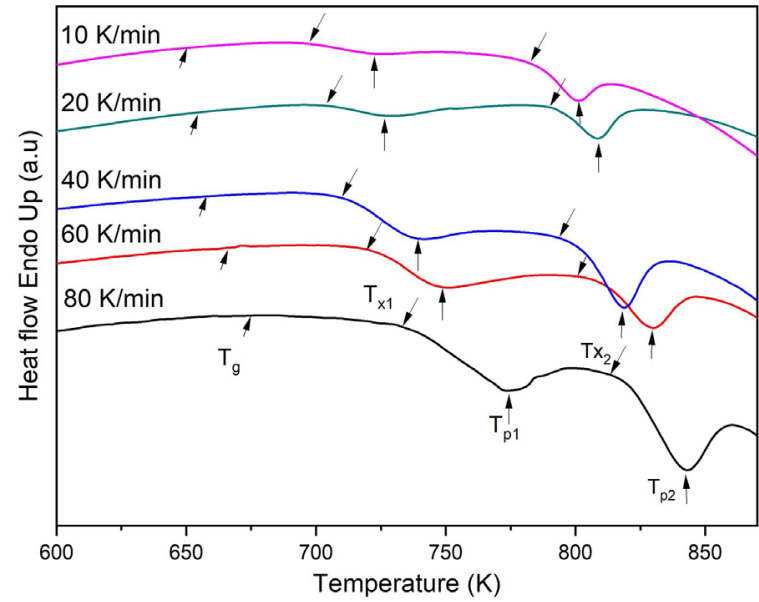

Figure 3. DSC curves of TiZrHfNiCu sample recording at various heating rates. 
Table 2. Atomic size ratios for the elements in alloys system [30].

\begin{tabular}{cccccc}
\hline & $\underline{\mathrm{Ti}}$ & $\underline{\mathrm{Zr}}$ & $\underline{\mathrm{Hf}}$ & $\underline{\mathrm{Cu}}$ & $\underline{\mathrm{Ni}}$ \\
\hline $\mathrm{Ti}$ & $\mathrm{X}$ & 10 & 9 & 15 & 18 \\
$\mathrm{Zr}$ & 10 & $\mathrm{X}$ & 1 & 27 & 30 \\
$\mathrm{Hf}$ & 9 & 1 & $\mathrm{X}$ & 25 & 28 \\
$\mathrm{Cu}$ & 15 & 27 & 25 & $\mathrm{X}$ & 2 \\
$\mathrm{Ni}$ & 18 & 30 & 28 & 2 & $\mathrm{X}$ \\
\hline
\end{tabular}

Table 3. Summary of sample diameter with phase identification from the XRD patterns.

\begin{tabular}{cc}
\hline Sample form & Phase Identification \\
\hline $3 \mathrm{~mm}$ rod & Crystalline \\
$2 \mathrm{~mm}$ rod & Partly amorphous \\
$1.5 \mathrm{~mm}$ rod & Amorphous \\
Ribbon $40 \mathrm{~m} / \mathrm{s}$ & Amorphous \\
\hline
\end{tabular}

Table 4. Characteristic temperature $\left(T_{g}, T_{x 1}, T_{p 1}, T_{x 2}, T_{p 2}\right.$ and $\left.\Delta T_{x}\right)$ for TiZrHfNiCu HE-BMG alloy at different heating rates.

\begin{tabular}{ccccccc}
\hline $\begin{array}{c}\text { Heating rate } \\
(\mathrm{K} / \mathrm{min})\end{array}$ & $\begin{array}{c}T_{g} \\
(\mathrm{~K})\end{array}$ & $\begin{array}{c}T_{x 1} \\
(\mathrm{~K})\end{array}$ & $\begin{array}{c}T_{p 1} \\
(\mathrm{~K})\end{array}$ & $\begin{array}{c}T_{x 2} \\
(\mathrm{~K})\end{array}$ & $\begin{array}{c}T_{p 2} \\
(\mathrm{~K})\end{array}$ & $\begin{array}{c}\Delta T_{x 1} \\
(\mathrm{~K})\end{array}$ \\
\hline 10 & 650.2 & 698.5 & 722.2 & 785.5 & 800.6 & 48.3 \\
20 & 654.4 & 706.6 & 726.1 & 792.7 & 806.3 & 52.3 \\
40 & 658.2 & 711.8 & 739.1 & 794.4 & 817.6 & 53.7 \\
60 & 666.6 & 723.2 & 748.2 & 802.8 & 830.8 & 56.7 \\
80 & 676.4 & 736.4 & 773.7 & 816.0 & 841.6 & 60.0 \\
\hline
\end{tabular}

Besides, it was also evident that $\Delta T_{X}$ increased from $48 \mathrm{~K}$ at $10 \mathrm{~K} / \mathrm{min}$ to $60 \mathrm{~K}$ at $80 \mathrm{~K} / \mathrm{min}$, which signified that nucleation was activated thermally; thus, crystallization was considerably dependent on the heating rate. Meanwhile, the glass transition temperature changed with the heating rate due to the relaxation process of the amorphous alloy in the supercooled liquid region. Remarkably, TiZrHfNiCu HE-BMG possessed a broader supercooled liquid region of $50 \mathrm{~K}$ at $20 \mathrm{~K} / \mathrm{min}$ heating rate as compared to $\mathrm{Sr}_{20} \mathrm{Ca}_{20} \mathrm{Yb}_{20} \mathrm{Ma}_{20} \mathrm{Zn}_{20} ; 36 \mathrm{~K}$ [33] but lower than TiZrHfNiBe; $66 \mathrm{~K}$ [5] and PdPtCuNiP; $65 \mathrm{~K}$ [34] at similar heating rate (20 $\mathrm{K} / \mathrm{min}$ ), which indicated a relatively good thermal stability of this currently produced alloy among the other HE-BMGs.

Besides, thermal stability of the amorphous alloys can be evaluated using two important kinetic parameters which are, apparent activation energy of glass transition $\left(E_{g}\right)$ and crystallization $\left(E_{x}\right) . E_{g}$ can be described as energy for transformation from the glassy phase to the supercooled liquid, $E_{x}$ is associated with the transformative energy of nucleation from the supercooled liquid state to the crystallization state. Another parameter, $E_{p}$ is essential to determine the energy for crystal growth. Therefore, a calculation of the apparent activation energy on each transformation event was conducted using two different equations; Kissin- 
ger and Ozawa which can be expressed as [21] [35],

Kissinger equation:

$$
\ln \frac{t^{2}}{\beta}=\frac{E}{R T}+\text { const }
$$

Ozawa equation:

$$
\ln \beta=\frac{E}{R T}+\text { const }
$$

where $\beta$ is the heating rate, $T$ denotes the characteristics temperatures at certain heating rate $\beta, R$ is the ideal gas constant, $E$ corresponds the average apparent activation energy for each crystallization events.

Activation energy can be defined as the energy required for an atom before it becomes a part of the activated cluster. The value of apparent activation energy for $E_{g}, E_{x 1}, E_{p 1}, E_{x 2}$, and $E_{p 2}$ can be obtained by the linear fitting method in Kissinger and Ozawa plot in Figure 4, and the values were listed in Table 5. From the table, it is evidently obvious that the apparent activation energy of glass transition and crystallization estimated from the Kissinger equation and Ozawa equation are reinforcing each other. It was noticed that, for the first crystallization event, the $E_{p 1}$ was smaller than $E_{x 1}$ in the Ozawa method, which explained that more energy was required for the nucleation than the grain growth process. However, Kissinger's value provided different results, where the value of $E_{p 1}$ was larger than $E_{x 1}$. This phenomenon might result in considerable $R^{2}$ value (0.878) of $E_{p 1}$ linear fitting in the Kissinger plot. Besides, $E_{x 2}>E_{x 1}$ shown in all analytical methods explained that high energy barrier in second crystallization compared to the first, implying that the first crystallization stage was much easier for nucleation to occur. Therefore, the estimated data above implied that nucleation and growth apparent energy for the first crystallization stage gave almost similar value. İ contrast, the difficulties of the growth process were much more significant in the second crystallization stage. The above statements were in agreement with the other crystallization kinetics studies in metallic glass alloys [5] [7] [38] [39].

The relatively high activation crystallization energy values in the second crystallization stage shows that a significant number of atoms participated from the glassy alloys in the structural reorganization during the second stage of the crystallization process. Besides, this phenomenon might be attributed to a sluggish diffusion in high entropy alloys, which resulted in difficulty for atomic diffusion [40]. It might also due to greater fluctuation of lattice potential energy that results in significant atomic traps and blocks, which can lead to high activation energy. Consequently, the nucleation and growth mechanism become slower due to the reduction of the nucleation rate that resulted from the sluggish diffusion. However, as compared to other reported HE-BMGs such as TiZrCuNiBe [5] and $\mathrm{Zr}_{41.2} \mathrm{Ti}_{13.8} \mathrm{Cu}_{12.5} \mathrm{Ni}_{10} \mathrm{Be}_{22.5}$ [37], the value of the apparent activation energy for TiZrHfNiCu was relatively small, indicated lower thermal stability of this alloy compared to the former alloys. 


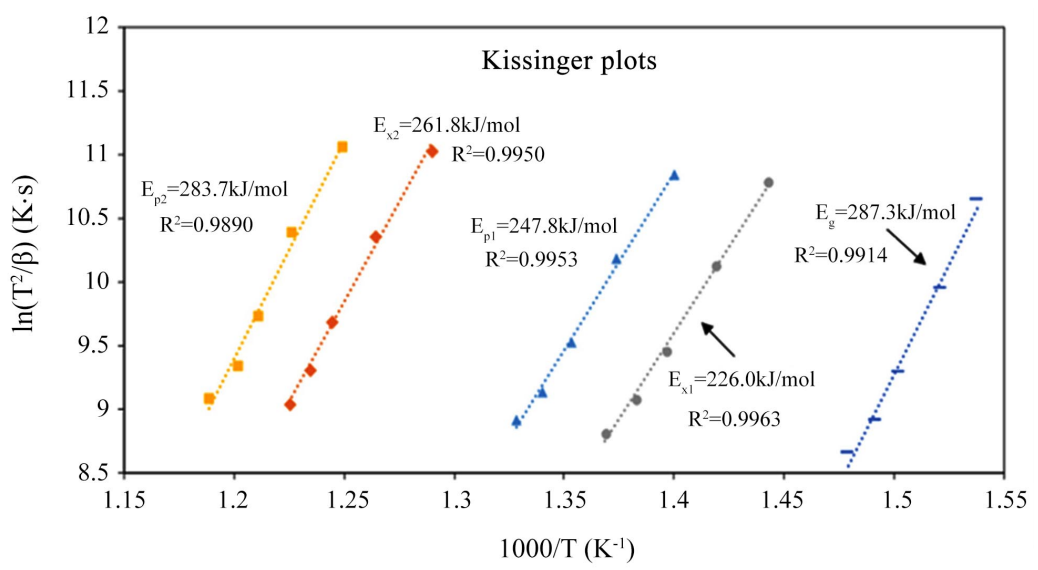

(a)

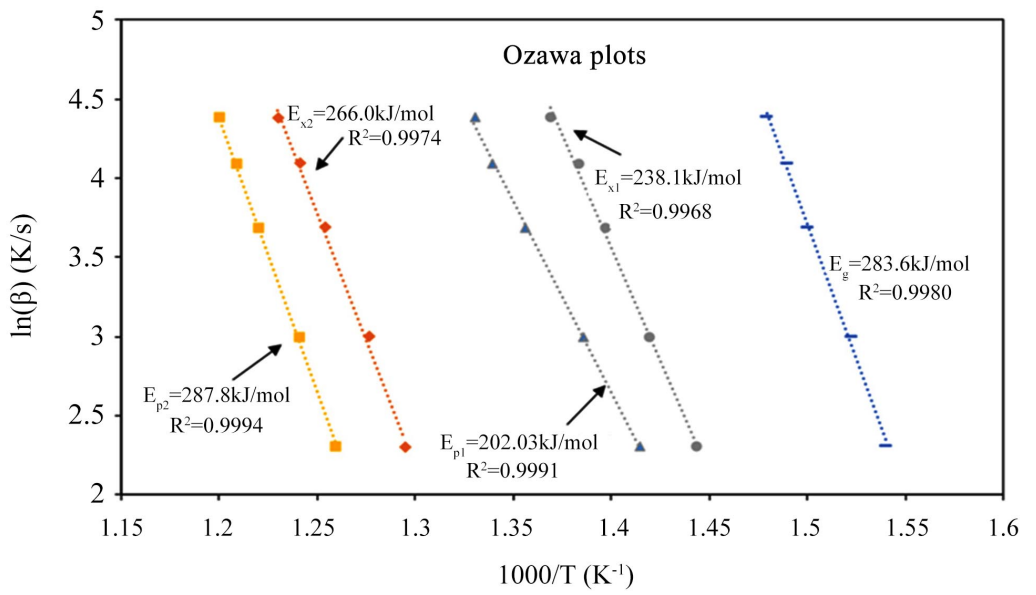

(b)

Figure 4. (a) Kissinger plot, (b) Ozawa plot of TiZrHfNiCu HE-BMG alloy.

Table 5. Apparent activation energy for the glass transition and crystallization by Kissinger method (KM) and Ozawa method (OM).

\begin{tabular}{ccccccc}
\hline & & & \multicolumn{2}{c}{ First stage } & \multicolumn{2}{c}{ Second stage } \\
\cline { 6 - 8 } Alloy & Method & $\begin{array}{c}E_{g} \\
(\mathrm{~kJ} / \mathrm{mol})\end{array}$ & $\begin{array}{c}E_{x 1} \\
(\mathrm{~kJ} / \mathrm{mol})\end{array}$ & $\begin{array}{c}E_{p 1} \\
(\mathrm{~kJ} / \mathrm{mol})\end{array}$ & $\begin{array}{c}E_{x 2} \\
(\mathrm{~kJ} / \mathrm{mol})\end{array}$ & $\begin{array}{c}E_{p 2} \\
(\mathrm{~kJ} / \mathrm{mol})\end{array}$ \\
\hline \multirow{2}{*}{ TiZrHfNiCu} & $\mathrm{KM}$ & 287 & 226 & 247 & 261 & 283 \\
& $\mathrm{OM}$ & 283 & 238 & 202 & 266 & 287 \\
TiZrCuNiBe [5] [36] & $\mathrm{KM}$ & 317 & 307 & 296 & 347 & 374 \\
$\mathrm{Zr}_{41.2} \mathrm{Ti}_{13.8} \mathrm{Cu}_{12.5} \mathrm{Ni}_{10} \mathrm{Be}_{22.5}$ & $\mathrm{OM}$ & 312 & 312 & 284.6 & 343 & 369 \\
{$[37]$} & $\mathrm{KM}$ & 535 & 162 & 203 & 271 & 301 \\
\hline
\end{tabular}

Figure 5(a) and Figure 5(b) show the crystallized volume fraction, $x$ for the first and second exothermic peaks was for TiZrHfNiCu HE-BMG with a dependence of temperature $\mathrm{T}$ at different heating rates. In contrast, Table 6 shows the listed value of local activation energy at each crystallization point. A sigmoid shape of the curves represented the difference of crystallization rate at different 
stages. In general, it was clearly shown that crystallization occurred at a slower rate at the beginning $(x<0.2)$, propagated at the middle $(0.2<x<0.9)$, and subsequently was slowed at the end of the process $(x<0.9)$. Therefore, it was suggested that the transformation was divided into three stages; 1$)$ the nuclei started to precipitate from the amorphous matrix slowly where the bulk crystallization played an important role; 2) subsequently increased the surface contact between nuclei and the amorphous matrix that caused the crystallized volume fraction to increase intensely and 3) finally the surface between the crystalline phase and amorphous matrix decreased due to grain coalescence [12]. The higher activation energy values at the middle stage $\left(E_{x 1}(0.5)=264.38 \mathrm{~kJ} / \mathrm{mol}\right.$ and $\left.E_{x 2}(0.5)=301.04\right)$ were due to the progressive crystallization growth, especially at the higher heating rate. This result was considered consistent with the most isokinetic studies of amorphous alloys [5] [38] [41] [42]. Noticeably, the average value of local activation energy of $E_{x 1}$ was smaller than $E_{x 2}$, which was in a consistency with the result of apparent activation energy.

Table 6. List of local activation energy at different crystallization fraction of the TiZrHfNiCu HE-BMG.

\begin{tabular}{ccc}
\hline$x$ & $E_{x 1}(x)(\mathrm{kJ} / \mathrm{mol})$ & $E_{x 2}(x)(\mathrm{kJ} / \mathrm{mol})$ \\
\hline 0.1 & 245.3 & 323.5 \\
0.2 & 250.6 & 307.2 \\
0.3 & 260.9 & 297.8 \\
0.4 & 258.1 & 295.2 \\
0.5 & 264.4 & 301.0 \\
0.6 & 261.6 & 293.7 \\
0.7 & 260.4 & 296.9 \\
0.8 & 246.1 & 284.0 \\
0.9 & 223.3 & 280.1 \\
Average & 226.4 & 297.7 \\
\hline
\end{tabular}

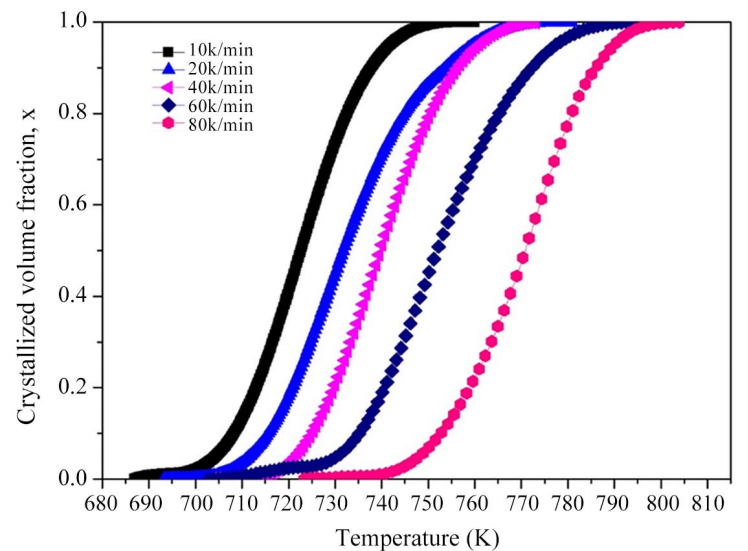

(a)

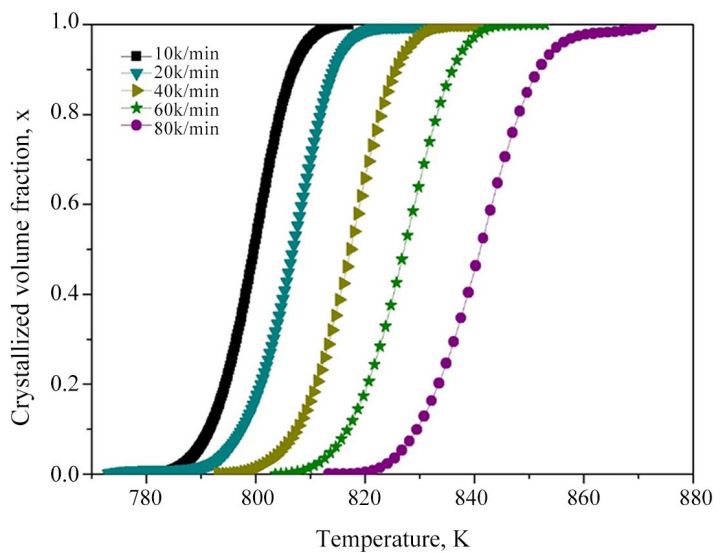

(b)

Figure 5. Plots of crystallized volume fraction $x$, versus temperature of TiZrHfNiCu HE-BMG at different heating rates for (a) first and (b) second crystallization events. 
Local Avrami exponent, $n(x)$, has been widely used to relatively measures the average value of crystallization transformation at specific conditions. The definition of "local" indicates the nucleation and growth behavior of the alloy at the specific crystallization volume fraction, $x$ [43]. In order to utilize the JMA equation for the non-isothermal crystallization process, several conditions need to be satisfied [12]. It was suggested that the crystallization peak temperature, $T_{p}$ of the alloy must occur at 0.60 to 0.63 range of crystallization volume fraction, $x$ [12]. For the present studies, the value of $x_{p}$ at $T_{p}$ was found in the range of 0.60 to 0.63 .

By plotting $\ln [-\ln (1-x)]$ versus $\ln \left[\left(T-T_{0}\right) / \beta\right]$, the $n$ values might be obtained from the slope of the graphs, as displayed in Figure 6. The values of the slope were listed in Table 7. The plot was found to be linear over most of the temperature range but slightly deviated at higher temperatures for all heating rates. The deviation could be due to the saturation of nucleation at the final stages of the crystallization process. Besides, this situation also resulted in crystal growth constraint for the small particles that restricted the nucleation process [44].

From the calculated JMA exponent, $n$, the value (which was the nucleation mode of the alloy) was proportionally increased as a function of heating rate in the first crystallization stage where it was initially more significant than 3 and subsequently increased to 4 . The $n$ value was not an integer, and it was equal to $n=m+1$. Therefore, the value of $m$ (which was an indicator of crystallization behavior) was equal to 2 but then increased to 3 at $60 \mathrm{~K} / \mathrm{min}$. The finding suggested that the growth mechanism changed from the interface-controlled two-dimensional growth to the diffusion-controlled three-dimensional growth with the increasing heating rate for the first crystallization process. In contrast, for the second stage, the $\mathrm{n}$ values were constant $(n=3)$ with an increased heating rate, which signified that the growth of crystallization two-dimensional growth with increasing nucleation rate at all heating rates. In this case, the activation energy is increased since the mechanism changed from the interfacecontrolled two-dimensional growth to the diffusion-controlled three-dimensional growth. On the other hand, the activation energy is much lower if the reaction is slower; thus, Avrami exponent is smaller [45]. It is known that the sluggish effect of HEA concerning the activation energy and pre-exponential factor determined by the Arrhenius equation. The high activation energy proved that a low grain growth rate occurs in the alloy, which reflects the pre-exponential factor value [40]. It is also found that the $n$ values increased in the first stage, but then became constant in the second stage as a function of heating rate. This is because the sluggish atomic diffusion of this alloy due to densely random packed atomic configuration of the structure of multicomponent alloy, particularly at higher temperatures (second stage), result in lower mobility of atomic diffusion, leading to lower nucleation rate compared to first crystallization stage for all heating rates. 


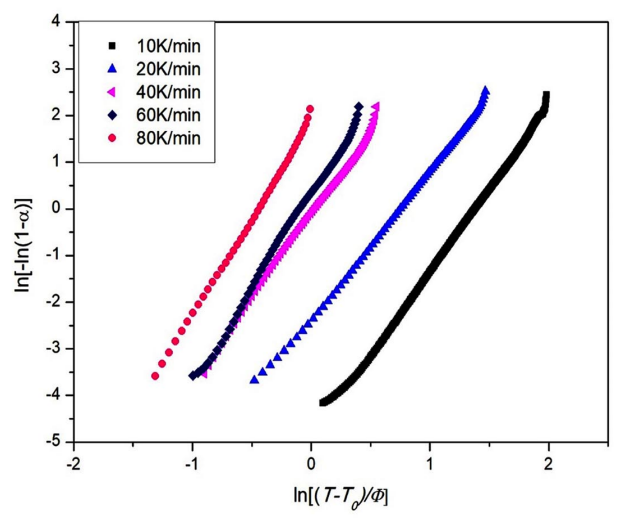

(a)

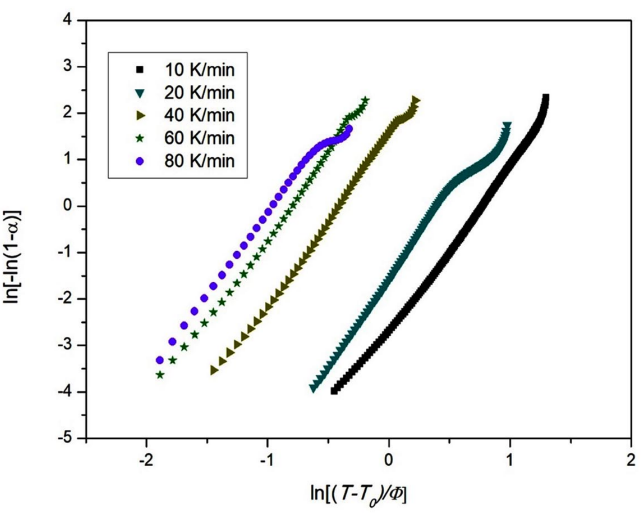

(b)

Figure 6. JMA plots of TiZrHfNiCu HE-BMG at different heating rates for (a) first and (b) second exothermic peaks.

Table 7. The value of $n$ and $m$ of Avrami exponent to determine nucleation modes and crystallization mechanism in the alloy respectively.

\begin{tabular}{ccc}
\hline & First crystallization stage & \\
\hline Heating rate & $n$ & $m(n=m+1)$ \\
\hline 10 & 3 & 2 \\
20 & 3 & 2 \\
40 & 3 & 3 \\
60 & 4 & 3 \\
80 & 4 & 2 \\
10 & Second crystallization stage & 2 \\
20 & 3 & 2 \\
40 & 3 & 2 \\
60 & 3 & 3 \\
80 & 3 & 2 \\
\hline
\end{tabular}

\section{Conclusion}

Kinetics of crystallization in TiZrHfNiCu HE-BMG was investigated by DSC method in non-isothermal condition. The information regarding activation energy and crystallization mechanism reflects the resistance of crystallization during heating. Two stages of the crystallization process were found under non-isothermal conditions. It was shown that $\mathrm{TiZrHfNiCu}$ has higher apparent activation energy $\left(E_{x 1}\right.$ and $E_{p 1}$ ) compared to conventional Zr-based alloys but lower than TiZrCuNiBe HE-BMG. It is suggested that high mixing entropy in TiZrHfNiCu alloy successfully retard lattice diffusion at higher temperatures in non-isothermal conditions, lead to a slow crystallization process. 


\section{Acknowledgements}

The authors thank the International Islamic University Malaysia (IIUM) and Ministry of Education grant no (FRGS19-094-0703) for the support of this research.

\section{Conflicts of Interest}

The authors declare no conflicts of interest regarding the publication of this paper.

\section{References}

[1] Chen, Shun, T., Yeh, J. and Wong, M. (2004) Nanostructured Nitride Films of Multi-Element High-Entropy Alloys by Reactive DC Sputtering. Surface and Coatings Technology, 188, 193-200. https://doi.org/10.1016/j.surfcoat.2004.08.023

[2] Cantor, B., Chang, I., Knight, P. and Vincent, A. (2004) Microstructural Development in Equiatomic Multicomponent Alloys. Materials Science and Engineering: $A$, 375, 213-218. https://doi.org/10.1016/j.msea.2003.10.257

[3] Suryanarayana, C. and Inoue, A. (2010) Bulk Metallic Glasses. CRC Press, Boca Raton. https://doi.org/10.1201/9781420085976

[4] Xing, Q.-W. and Zhang, Y. (2014) Amorphous Phase Formation Rules in High-Entropy Alloys. Chinese Physics B, 26, Article ID: 018104.

https://doi.org/10.1088/1674-1056/26/1/018104

[5] Gong, P., Yao, K.F. and Ding, H.Y. (2015) Crystallization Kinetics of TiZrHf-CuNiBe High Entropy Bulk Metallic glass. Materials Letters, 156, 146-149. https://doi.org/10.1016/j.matlet.2015.05.018

[6] Mostafa Shalaby, R., Kamal, M., Ali, E.A.M. and Gumaan, M.S. (2017) Microstructural and Mechanical Characterization of Melt Spun Process Sn-3.5Ag and Sn-3.5Ag-xCu Lead-Free Solders for Low Cost Electronic Assembly. Materials Science and Engineering. A, 690, 446-452. https://doi.org/10.1016/j.msea.2017.03.022

[7] Qiao, J.C. and Pelletier, J.M. (2011) Crystallization Kinetics in $\mathrm{Cu}_{46} \mathrm{Zr}_{45} \mathrm{Al}_{7} \mathrm{Y}_{2}$ Bulk Metallic Glass by Differential Scanning Calorimetry (DSC). Journal of Non-Crystalline Solids, 357, 2590-2594. https://doi.org/10.1016/j.jnoncrysol.2010.12.071

[8] Song, M. and He, Y. (2011) Effect of Isothermal Annealing on the Compressive Strength of a ZrAlNiCuNb Metallic Glass. Journal of Alloys and Compounds, 509, 2606-2610. https://doi.org/10.1016/j.jallcom.2010.11.114

[9] Hernández-Sánchez, F., Del Castillo, L.F. and Vera-Graziano, R. (2004) Isothermal Crystallization Kinetics of Polypropylene by Differential Scanning Calorimetry. I. Experimental Conditions. Journal of Applied Polymer Science, 92, 970-978. https://doi.org/10.1002/app.20033

[10] Jang, J.S.C., Chang, L.J., Chen, G.J. and Huang, J.C. (2005) Crystallization Behavior of the $\mathrm{Zr}_{63} \mathrm{Al}_{7.5} \mathrm{Cu}_{17.5} \mathrm{Ni}_{10} \mathrm{~B}_{2}$ Amorphous Alloy during Isothermal Annealing. Intermetallics, 13, 907-911. https://doi.org/10.1016/j.intermet.2004.12.025

[11] Martin, I., Ohkubo, T., Ohnuma, M., Deconihout, B. and Hono, K. (2004) Nanocrystallization of $\mathrm{Zr}_{41.2} \mathrm{Ti}_{13.8} \mathrm{Cu}_{12.5} \mathrm{Ni}_{10.0} \mathrm{Be}_{22.5}$ Metallic Glass. Acta Materialia, 52, 4427-4435. https://doi.org/10.1016/j.actamat.2004.05.038

[12] Henderson, D.W. (1979) Thermal Analysis of Non-Isothermal Crystallization Kinetics in Glass Forming Liquids. Journal of Non-Crystalline Solids, 30, 301-315. 
https://doi.org/10.1016/0022-3093(79)90169-8

[13] Zhang, L.C., Xu, J. and Eckert, J. (2006) Thermal Stability and Crystallization Kinetics of Mechanically Alloyed TiC/Ti-Based Metallic Glass Matrix Composite. Journal of Applied Physics, 100, Article ID: 033514. https://doi.org/10.1063/1.2234535

[14] Zou, L.M., Li, Y.H., Yang, C., Qu, S.G. and Li, Y.Y. (2013) Effect of Fe Content on Glass-Forming Ability and Crystallization Behavior of a $\left(\mathrm{Ti}_{69.7} \mathrm{Nb}_{23.7} \mathrm{Zr}_{4.9} \mathrm{Ta}_{1.7}\right)_{100-\mathrm{x}} \mathrm{Fe}_{x}$ Alloy Synthesized by Mechanical Alloying. Journal of Alloys and Compounds, 553, 40-47. https://doi.org/10.1016/j.jallcom.2012.10.154

[15] Dos Santos, D.S. and Dos Santos, D.R. (2002) Crystallization Kinetics of Fe-B-Si Metallic Glasses. Journal of Non-Crystalline Solids, 304, 56-63. https://doi.org/10.1016/S0022-3093(02)01004-9

[16] Wang, H.R., Gao, Y.L., Ye, Y.F., Min, G.H., Chen, Y. and Teng, X.Y. (2003) Crystallization Kinetics of an Amorphous $\mathrm{Zr}-\mathrm{Cu}-\mathrm{Ni}$ Alloy: Calculation of the Activation Energy. Journal of Alloys and Compounds, 353, 200-206. https://doi.org/10.1016/S0925-8388(02)01208-2

[17] Yuan, Z.Z., Chen, X.D., Wang, B.X. and Chen, Z.J. (2005) Crystallization Kinetics of Melt-Spun $\mathrm{Co}_{43} \mathrm{Fe}_{20} \mathrm{Ta}_{5.5} \mathrm{~B}_{31.5}$ Amorphous Alloy. Journal of Alloys and Compounds, 399, 166-172. https://doi.org/10.1016/j.jallcom.2005.03.026

[18] Ozawa, T. (1971) Kinetics of Non-Isothermal. Polymer, 12, 150-158. https://doi.org/10.1016/0032-3861(71)90041-3

[19] Kissinger, H.E. (1956) Variation of Peak Temperature with Heating Rate in Differential Thermal Analysis. Journal of Research of the National Bureau of Standards, 57, 217-221. https://doi.org/10.6028/jres.057.026

[20] Augis, J.A. and Bennett, J.E. (1978) Calculation of the Avrami Parameters for Heterogeneous Solid State Reactions Using a Modification of the Kissinger Method. Journal of Thermal Analysis, 13, 283-292. https://doi.org/10.1007/BF01912301

[21] Kissinger, H.E. (1957) Reaction Kinetics in Differential Thermal Analysis. Analytical Chemistry, 29, 1702-1706. https://doi.org/10.1021/ac60131a045

[22] Narayanaswamy, O.S. (1971) A Model of Structural Relaxation in Glass. Journal of the American Ceramic Society, 54, 491-498. https://doi.org/10.1111/j.1151-2916.1971.tb12186.x

[23] Tool, A.Q. (1946) Relation between Inelastic Deformability and Thermal Expansion of Glass in Its Annealing Range. Journal of the American Ceramic Society, 29, 240-253. https://doi.org/10.1111/j.1151-2916.1946.tb11592.x

[24] Svoboda, R., Čičmanec, P. and Málek, J. (2013) Kissinger Equation versus Glass Transition Phenomenology. Journal of Thermal Analysis and Calorimetry, 114, 285-293. https://doi.org/10.1007/s10973-012-2892-3

[25] Bizhanova, G., Li, F., Ma, Y., Gong, P. and Wang, X. (2019) Development and Crystallization Kinetics of Novel Near-Equiatomic High-Entropy Bulk Metallic Glasses. Journal of Alloys and Compounds, 779, 474-486. https://doi.org/10.1016/j.jallcom.2018.11.299

[26] Ma, L., Wang, L., Zhang, T. and Inoue, A. (2002) Bulk Glass Formation of Ti-ZrHf-Cu-M (M = Fe, Co, Ni) Alloys. Materials Transactions, 43, 277-280. https://doi.org/10.2320/matertrans.43.277

[27] Inoue, A. (2000) Stabilization of Metallic Supercooled Liquid and Bulk Amorphous Alloys. Acta Materialia, 48, 279-306. https://doi.org/10.1016/S1359-6454(99)00300-6 
[28] Guo, S. and Liu, C.T. (2011) Phase Stability in High Entropy Alloys: Formation of Solid-Solution Phase or Amorphous Phase. Progress in Natural Science: Materials International, 21, 433-446. https://doi.org/10.1016/S1002-0071(12)60080-X

[29] Cunliffe, A., Plummer, J., Figueroa, I. and Todd, I. (2012) Glass Formation in a High Entropy Alloy System by Design. Intermetallics, 23, 204-207. https://doi.org/10.1016/j.intermet.2011.12.006

[30] Takeuchi, A. and Inoue, A. (2000) Calculations of Mixing Enthalpy and Mismatch Entropy for Ternary Amorphous Alloys. Materials Transactions, JIM, 41, 1372-1378. https://doi.org/10.2320/matertrans1989.41.1372

[31] Pelletier, J.-M. and Van de Moortèle, B. (2003) Phase Separation and Crystallization in the $\mathrm{Zr}_{41.2}-\mathrm{Ti}_{13.8}-\mathrm{Cu}_{12.5}-\mathrm{Ni}_{10}-\mathrm{Be}_{22.5}$ Bulk Metallic Glass Determined by Physical Measurements and Electron Microscopy. Journal of Non-Crystalline Solids, 325, 133-141. https://doi.org/10.1016/S0022-3093(03)00322-3

[32] Höhne, G.W.H., Hemminger, W.F. and Flammersheim, H.-J. (2003) Differential Scanning Calorimetry. Springer, Berlin. https://doi.org/10.1007/978-3-662-06710-9

[33] Li, H.F., Xie, X.H., Zhao, K., Wang, Y.B., Zheng, Y.F., Wang, W.H. and Qin, L. (2013) In Vitro and in Vivo Studies on Biodegradable CaMgZnSrYb High-Entropy Bulk Metallic Glass. Acta Biomaterialia, 9, 8561-8573. https://doi.org/10.1016/j.actbio.2013.01.029

[34] Takeuchi, A., Chen, N., Wada, T., Yokoyama, Y., Kato, H., Inoue, A. and Yeh, J.W. (2011) $\mathrm{Pd}_{20} \mathrm{Pt}_{20} \mathrm{Cu}_{20} \mathrm{Ni}_{20} \mathrm{P}_{20}$ High-Entropy Alloy as a Bulk Metallic Glass in the Centimeter. Intermetallics, 19, 1546-1554. https://doi.org/10.1016/j.intermet.2011.05.030

[35] Ozawa, T. (1965) A New Method of Analyzing Thermogravimetric Data. Bulletin of the Chemical Society of Japan, 38, 1881-1886. https://doi.org/10.1246/bcsj.38.1881

[36] Gong, P., Zhao, S., Ding, H., Yao, K. and Wang, X. (2015) Nonisothermal Crystallization Kinetics, Fragility and Thermodynamics of $\mathrm{Ti}_{20} \mathrm{Zr}_{20} \mathrm{Cu}_{20} \mathrm{Ni}_{20} \mathrm{Be}_{20}$ High Entropy Bulk Metallic Glass. Journal of Materials Research, 30, 2772-2782. https://doi.org/10.1557/jmr.2015.253

[37] Song, K.K., Gargarella, P., Pauly, S., Ma, G.Z., Kühn, U. and Eckert, J. (2012) Correlation between Glass-Forming Ability, Thermal Stability, and Crystallization Kinetics of Cu-Zr-Ag Metallic Glasses. Journal of Applied Physics, 112, Article ID: 063503. https://doi.org/10.1063/1.4752263

[38] Hemphill, M.A., Yuan, T., Wang, G.Y., Yeh, J.W., Tsai, C.W., Chuang, A. and Liaw, P.K. (2012) Fatigue Behavior of $\mathrm{Al}_{0.5} \mathrm{CoCrCuFeNi}$ High Entropy Alloys. Acta Materialia, 60, 5723-5734. https://doi.org/10.1016/j.actamat.2012.06.046

[39] Hiki, Y., Tanahashi, M., Tamura, R., Takeuchi, S. and Takahashi, H. (2007) Stabilization of Metallic Glass by Isochronal and Isothermal Annealing Treatments. Journal of Physics: Condensed Matter, 19, Article ID: 205147. https://doi.org/10.1088/0953-8984/19/20/205147

[40] Tsai, K.-Y., Tsai, M.-H. and Yeh, J.-W. (2013) Sluggish Diffusion in Co-Cr-FeMn-Ni High-Entropy Alloys. Acta Materialia, 61, 4887-4897.

https://doi.org/10.1016/j.actamat.2013.04.058

[41] Li, Y., Yang, C., Kang, L., Zhao, H., Qu, S., Li, X., Zhang, W. and Li, Y. (2016) Non-Isothermal and Isothermal Crystallization Kinetics and Their Effect on Microstructure of Sintered and Crystallized TiNbZrTaSi Bulk Alloys. Journal of NonCrystalline Solids, 432, 440-452. https://doi.org/10.1016/j.jnoncrysol.2015.11.005

[42] Kasyap, S., Patel, A.T. and Pratap, A. (2014) Crystallization Kinetics of $\operatorname{Ti}_{20} \mathrm{Zr}_{20} \mathrm{Cu}_{60}$ 
Metallic Glass by Isoconversional Methods Using Modulated Differential Scanning Calorimetry. Journal of Thermal Analysis and Calorimetry, 116, 1325-1336. https://doi.org/10.1007/s10973-014-3753-Z

[43] Calka, A. and Radlinski, A.P. (1988) The Local Value of the Avrami Exponent: A New Approach to Devitrification of Glassy Metallic Ribbons. Materials Science and Engineering, 97, 241-246. https://doi.org/10.1016/0025-5416(88)90050-X

[44] Colmenero, J. and Barandiaran, J. (1979) Crystallization of $\mathrm{Al}_{23} \mathrm{Te}_{77}$ Glasses. Journal of Non-Crystalline Solids, 30, 263-271. https://doi.org/10.1016/0022-3093(79)90165-0

[45] Lu, K. and Wang, J.T. (1991) Activation Energies for Crystal Nucleation and Growth in Amorphous Alloys. Materials Science and Engineering. A, 133, 500-503. https://doi.org/10.1016/0921-5093(91)90119-8 